of the seed-plants do not appear to fit into this conception in even an approximately satisfactory manner.

Laboratories of Plant Morphology, HARVARD UNIVERSITY

\section{RIVER-BANK MOVEMENTS DUE TO THE EARTH'S ROTATION}

To the Editor of Science: In Science, March 17, Mr. O. E. Jennings calls attention to a difference between the east and west banks of one of the short streams flowing across the almost flat southern slope of Long Island: "An almost imperceptibly sloping eastern bank and a western bank rising quite steeply." Mr. Jennings says, "This peculiar situation has long been accepted rather generally by geologists and physiographers as due to the westerly deflection of streams by the earth's rotation" (italics mine). The statement just quoted is doubtless an accidental slip. The fact is that because of the earth's rotation longitudinal rivers in the northern hemisphere erode their right banks-whether they flow south or north.

In offering another hypothesis for those Long Island banks Mr. Jennings makes the justifiable suggestion that the stream in question-as regards length and velocity-is incompetent for securing through the earth's rotation the effects observed. If it has a narrow channel and carries a small volume of water these items should be added to its other disqualifications. And finally, the latitude of Long Island-less than half the distance from the Equator to the North Pole-is none too favorable for river-bank movement due to the earth's behavior as a heavenly body.

In this connection reference may here be made to the unquestionable evidence of the earth's rotation afforded by the Yenisei. There is probably nowhere else in the world any other stream so favorable for the study of bank movement on a vast scale. This for three reasons: This Siberian river is closely longitudinal; of great size; and so far north that a considerable section of it lies within the Arctic Circle. Dr. Fridtjof Nansen, who has sailed up this river from its mouth to Yeniseisk-a distance of more than a thousand mileswrites of the very pronounced contrast be- tween the east and west banks. "Every one going up the Yenisei must be struck with the remarkable difference between the east and west sides of the river. While the flat land on the east is comparatively high and falls abruptly with a steep bank to the river, a steeply sloping beach and relatively deep water outside, the land on the west is strikingly low. The steep river bank is not high, and the bare sandy beach slopes quite gently to the water, with a shelving bottom far beyond it, so that as a rule it is not easy to approach this shore in a ship or boat." And again, "It is striking how. much higher and steeper the east bank is than the west everywhere along here."

Dr. Nansen's observations ${ }^{1}$ of this northern river and his discussion of what he saw forms a distinct contribution to the literature of the subject of such river-bank movements as are to be referred to the rotation of the earth.

Wellesley, Mass.

Elien Hayes

\section{THE DECOMPOSITION OF TUNGSTEN}

Sir ERNEST RUTherford, in the statement copied from Nature in the April 21 issuè of ScIEnCE, was in the very difficult position of being "asked to say a few words" in comment on a brief cablegram to the London Times which was itself based on an exaggerated Associated Press dispatch to American newspapers concerning the preliminary and oral but as yet unpublished report of $\mathrm{Mr}$. Clarence E. Irion and myself on the apparent decomposition of tungsten at extremely high temperatures. $\mathrm{He}$ mentions the need of a complete report before intelligent comment is possible, but proceeds to make three points which are properly conservative and entirely correct but, as will be seen from the complete paper upon its publication in the Journal of the American Chemical Society, which are all irrelevant. In view of the publicity given to Sir Ernest's comments in Nature and in ScIEnce, however, a few words in reply are needed.

The first point is that the appearance of helium has often been observed in electrical

1 Nansen, Fridtjof: Thirough Siberia, the Land of the Future, $71,72,73$, and 157,158 , ete. . 